\title{
Hyperosmolar Hyperglycemic Syndrome with Rhabdomyolysis
}

\author{
MARY E STUNKARD, VALERIE T PIKUL, KEVIN FOLEY
}

\begin{abstract}
In this report we describe a patient who presented with nausea, vomiting, diarrhea, tachypnea and mental impairment. The patient had elevated serum lipase, troponin-I, creatinine kinase and myoglobin along with severe hyperglycemia (> 2000 $\mathrm{mg} / \mathrm{dl}$ ) and no ketouria. This patient was found to have nonketotic hyperosmolar hyperglycemia with concomitant rhabdomyolysis and myocardial infarction.
\end{abstract}

INDEX TERMS: case study, electrolytes, osmolality, ketones

ABBREVIATIONS: CK, creatine phosphokinase, CT, computed axial tomography, DKA, diabetic ketoacidosis, HHS, hyperosmolar hyperglycemic syndrome, BUN, blood urea nitrogen, GFR, glomerular filtration rate, TnI, troponin-I, WBC, white blood cell count.

Clin Lab Sci 2011;24(1):8

Mary E. Stunkard, PhD, Department of Clinical Sciences, Northern Michigan University, Marquette, MI

Valerie T. Pikul, Department of Clinical Sciences, Northern Michigan University, Marquette, MI

Kevin Foley, PhD, MT, Kaiser Permanente Northwest Regional Laboratory, Portland, OR

Address for correspondence: Mary E. Stunkard PhD, Northern Michigan University, 1401 Presque Isle Avenue, 3511 West Science Building, Marquette, MI, 49855, 906-227-1662,mstunkar@nmu.edu.

\section{INTRODUCTION}

A 40-year-old Caucasian male was brought to the emergency department after being found lying on the bathroom floor, disorientated, hyperventilating and unable to get up. He had been experiencing flu-like symptoms with nausea, vomiting and diarrhea for the past five days. His wife reported that he had limited intake of fluids and solids. The patient had no reportable medical history, had not seen a doctor for years, was taking no medications, and reported to neither consume alcohol nor smoke cigarettes. He did have a family history significant for diabetes and hypertension.

Physical examination revealed a blood pressure of $154 / 80$, heart rate 130 , temperature $101.7^{\circ} \mathrm{F}\left(38.7^{\circ} \mathrm{C}\right)$, a respiratory rate of 48 , and morbid obesity. Chest excursion was fair with loose wheezes and rhonchi bilaterally. All other assessments were unremarkable. The patient was admitted to the intensive care unit. Shortly after admission, the patient became significantly tachypneic and increasingly lethargic. At that time he was sedated and intubated for airway protection.

Initial laboratory results revealed a critically-elevated blood glucose of $2040 \mathrm{mg} / \mathrm{dl}$ and an arterial $\mathrm{pH}$ of 7.21 (Table 1). Subsequent labwork revealed an elevated serum lipase, TnI, CK and myoglobin. Urinalysis results were positive for glucose and the presence of moderate hemoglobin without red cells present microscopically. Urine ketones were negative. Blood and urine cultures were taken which were later found to be negative. Sputum and urethral cultures were positive for Candida albicans.

\section{DISCUSSION}

The most striking laboratory findings concerning this patient are the extremely elevated blood glucose with acidosis and concomitant increases in CK and myoglobin. While a diagnosis of diabetic ketoacidosis (DKA) seems plausible, this diagnosis is not consistent 


\section{CLINICAL PRACTICE}

Table 1: Patient Laboratory Results

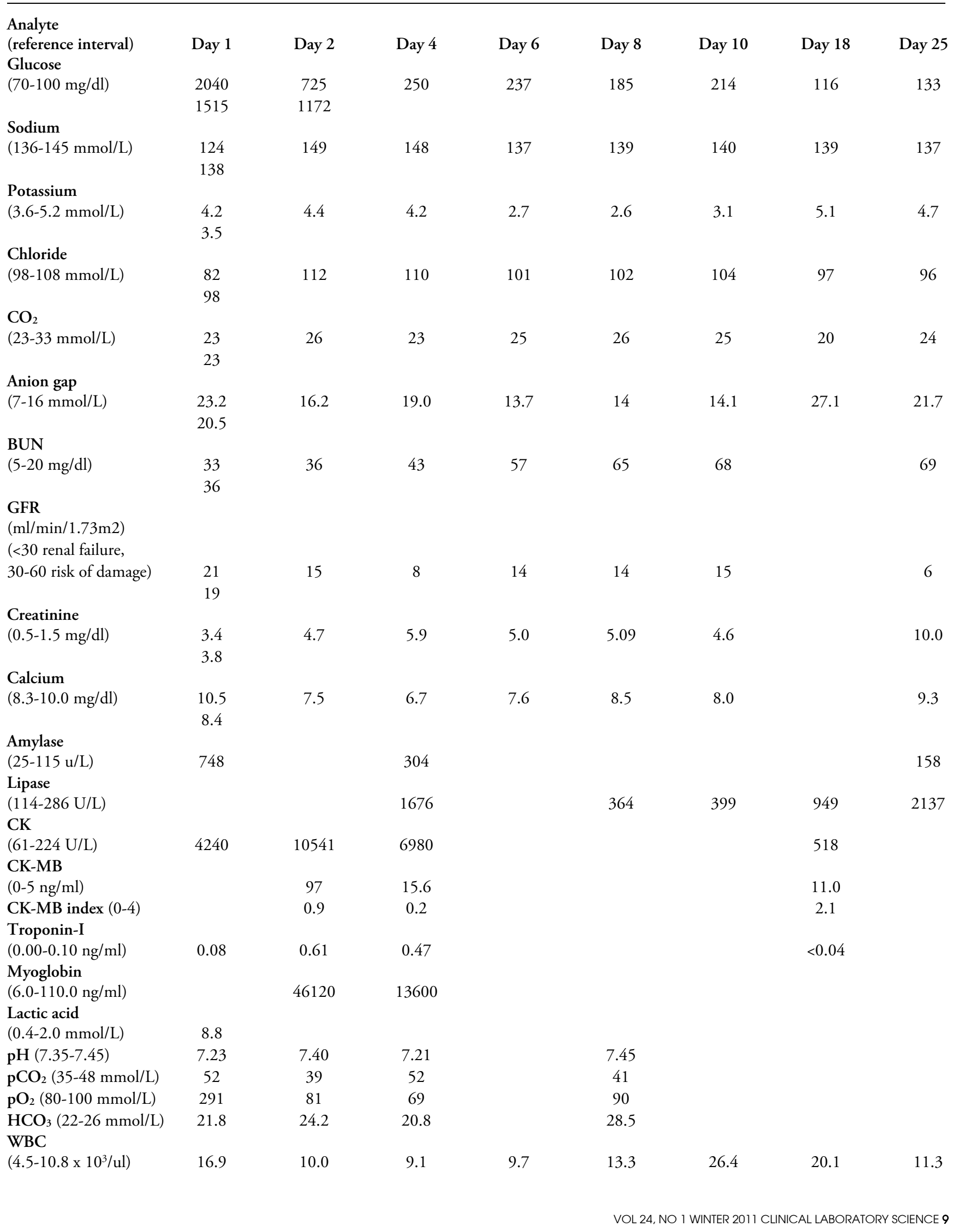




\section{CLINICAL PRACTICE}

with the lack of ketouria. A less well-known but not uncommon sequella of undiagnosed diabetes mellitus is hyperosmolar hyperglycemic syndrome (HHS). The term HHS has replaced 'hyperglycemic hyperosmolar non-ketotic coma' and 'hyperglycemic hyperosmolar non-ketotic state' since coma is not always seen and mild to moderate ketosis can be present in HHS. While the symptoms of DKA and HHS often overlap, HHS is unique in that it presents with markedly increased plasma glucose (greater than $600 \mathrm{mg} / \mathrm{dl}$ ), an effective serum osmolality over $320 \mathrm{mOsm} / \mathrm{kg}$, profound dehydration and mild to absent ketosis. ${ }^{1}$ This patient's glucose of $2040 \mathrm{mg} / \mathrm{dl}$ with a lack of urinary ketones coupled with a calculated osmolality of $365 \mathrm{mOsm} / \mathrm{kg}$ is highly suggestive of HHS.

Both HHS and DKA can occur in either type-1 or type2 diabetes. However, DKA is more commonly seen in patients with type-1 diabetes and HHS is more common in patients with type- 2 diabetes. ${ }^{2}$ Table 2 lists common features of DKA and HHS.

There are a number of predisposing factors in the development of HHS but underlying infection appears to be the most common. ${ }^{3}$ In this patient, pancreatitis was the stressor suspected to have triggered the HHS episode as evidenced by the elevated amylase, lipase and
WBC. An abdominal and pelvic CT revealed peripancreatic stranding and edema, findings consistent with pancreatitis. The patient's complaints of nausea and vomiting during the previous five days, symptomatic of pancreatitis, likely initiated mild dehydration which, coupled with his underlying, undiagnosed diabetes, led to the development of HHS. The primary mechanism for development of HHS is a reduction in effective levels of insulin coupled with concomitant elevation of the counter-regulatory hormone glucagon, and stress-induced catecholamines, cortisol and growth hormone. ${ }^{4}$ Glucose, which is already elevated in uncontrolled diabetes, is further elevated by these hormones which promote gluconeogenesis and enhance glycogenolysis.

It has been established that the renal threshold for glucose is approximately $180 \mathrm{mg} / \mathrm{dl}$ for a healthy adult. ${ }^{5}$ When blood glucose levels rise above this point, the ability of the renal tubules to reabsorb glucose is overwhelmed resulting in osmotic diuresis that leads to dehydration. Osmotic diuresis also leads to loss of electrolytes, especially the cations sodium, potassium and magnesium. An initial dilutional effect also occurs when water is pulled from the intracellular compartment in response to the high levels of glucose

Table 2: Differentiation between Diabetic Ketoacidosis and HHS

\begin{tabular}{|c|c|c|}
\hline & Diabetic Ketoacidosis (DKA) & Hyperosmolar Hyperglycemic Syndrome (HHS) \\
\hline Diabetic association & Type 1 & Type 2 \\
\hline Onset & $\begin{array}{l}\text { Typically develops over short period } \\
\text { of time, less than } 24 \text { hours }\end{array}$ & Insidious onset of days to weeks \\
\hline Precipitating factors & Poor glucose control / compliance & $\begin{array}{l}\text { Possible drug contribution (phenytoin, } \\
\text { diuretics, corticosteroids) }\end{array}$ \\
\hline Signs/symptoms & $\begin{array}{l}\text { Polyuria, polydipsia, nausea, vomiting, } \\
\text { abdominal pain, weakness }\end{array}$ & $\begin{array}{l}\text { Dehydration, volume depletion, } \\
\text { polyuria, polydipsia }\end{array}$ \\
\hline Blood urea nitrogen & $<25 \mathrm{mg} / \mathrm{dl}$ & $>30 \mathrm{mg} / \mathrm{dl}$ \\
\hline Osmolality & $<320 \mathrm{mOsm} / \mathrm{kg}$ & $>320 \mathrm{mOsmol} / \mathrm{kg}$ \\
\hline $\mathrm{pH}$ & $<7.2$ & $>7.3$ \\
\hline $\mathrm{HCO}_{3}^{-}$ & $<15 \mathrm{mmol} / \mathrm{L}$ & $>15 \mathrm{mmol} / \mathrm{L}$ \\
\hline Glucose & $>250 \mathrm{mg} / \mathrm{dl}$ & $>600 \mathrm{mg} / \mathrm{dl}$ \\
\hline Ketones & Urine: $3+$ & Urine: absent or small \\
\hline & Serum: $1+$ & Serum: absent or small \\
\hline Mental status & Mental obtundation less common & $\begin{array}{l}\text { Mental obtundation common, seizures } \\
\text { possible }\end{array}$ \\
\hline Body water deficit & $5-7 \mathrm{~L}$ & $10+\mathrm{L}$ \\
\hline
\end{tabular}




\section{CLINICAL PRACTICE}

which are restricted to the extracellular compartment. Most significantly, this effectively dilutes extracellular plasma sodium by a ratio of $1.6 \mathrm{mmol} / \mathrm{L}$ for every 100 $\mathrm{mg} / \mathrm{dl}$ increase of plasma glucose above normal. To correct for this false or transitional hyponatremia, the following equation is used: ${ }^{1}$ Corrected sodium $(\mathrm{mEq} / \mathrm{L})$ $=$ Measured sodium $+(0.16 \times$ (serum glucose $\mathrm{mg} / \mathrm{dl}-$ 100/100)). In this patient, the initial blood sample had a sodium concentration of $124 \mathrm{mmol} / \mathrm{L}$. To correct for the hyperglycemia: corrected sodium $=124+(0.16 \mathrm{x}$ $(2040-100 / 100))=155 \mathrm{mEq} / \mathrm{L}$.

The corrected sodium should be taken into consideration when selecting the solutions used for rehydration. As is the case with this patient, if the corrected serum sodium is high, $0.45 \% \mathrm{NaCl}$ is administered initially. ${ }^{1}$ The sodium concentration will typically return to normal once the blood glucose concentration is lowered and fluid balance is restored. Adequate fluid replacement is indicated by a drop in serum glucose of $75-100 \mathrm{mg} / \mathrm{dl} / \mathrm{hr}$ regardless of insulin administration. ${ }^{6}$

Blood potassium levels are also affected by hyperglycemia and acidosis. Acidosis leads to a shift of intracellular potassium into the extracellular space where it may then be lost in urine or vomit. Plasma potassium levels may therefore appear normal despite decreased whole body potassium levels. When therapy with insulin and fluids ensues, dramatic shifts in potassium, as well as glucose, occur from the plasma to the intracellular space, creating hypokalemia and the potential for cardiac arrhythmias, which must be closely monitored. ${ }^{4}$ To replace potassium losses, potassium should be given with an anion such as phosphate, which distributes to the intracellular fluid rather than chloride which is predominately extracellular. ${ }^{1}$ In this patient, the initial potassium level of $4.2 \mathrm{mmol} / \mathrm{L}$ dropped to $3.5 \mathrm{mmol} / \mathrm{L}$ when insulin was administered and further dropped to $2.6 \mathrm{mmol} / \mathrm{L}$ over the next 6 days before rebounding to reference range during days 18-25. Full correction of potassium levels often require days to weeks of steady anabolism. ${ }^{6}$

It would seem intuitive that fatty-acid oxidation and accompanying ketones would be present in hyperglycemic cases such as this. However this is often not the case in HHS and the reasons for this phenomenon is not fully understood. The absence of fatty-acid oxidation and ketone production no doubt arises from dysfunctional endocrine regulation of metabolic pathways. Although insulin is present, it is not sufficient to reduce blood glucose levels to normal ranges, especially in cases of insulin resistance. However, it is possible that the presence of insulin does allow for some fraction of glucose uptake to occur and thus ketone production is limited. ${ }^{2}$ Also, the higher concentration of insulin in HHS as compared to DKA, may be sufficient to inhibit the action of hormone sensitive lipase, thus thwarting triglyceride breakdown to ketones in adipose tissue. ${ }^{4}$

While the urine dipstick results in this patient were negative for ketones, it is important to recall that the urine dipstick assay detects acetoacetic acid but not the other ketones, acetone and beta -hydroxybutyric acid. ${ }^{7}$ Since beta-hydrodroxybutyrate tends to be $2-3$ times higher than acetoacetate in ketosis, it is advisable to use other indicators of ketosis such as quantitative blood ketones. $^{8}$

HHS can also be differentiated from DKA by serum $\mathrm{pH}$. Typically HHS patients have $\mathrm{pH}$ values > 7.3. In this patient lactic acidosis, as evidenced by a blood lactate of $8.8 \mathrm{mmol} / \mathrm{L}$ and an elevated anion gap, is present. The metabolic acidosis is compensated by tachypnea, and is likely due to both an overproduction of lactic acid and delayed clearance of inorganic acids due to renal hypoperfusion. ${ }^{4}$

This patient developed rhabdomyolysis, the acute and massive release of myoglobin, potassium, lactic dehydrogenase, CK and other constituents of skeletal muscle into the blood and urine. Rhabdomyolysis is known to occur in HHS and can also be associated with a myriad of other conditions including crush injuries, infection, and medication. ${ }^{9}$ The hyperosmolarity associated with HHS is thought to reduce the integrity of the sarcolemma leading to the loss of ionic gradients across the cell membrane. This in turn leads to increased levels of intracellular calcium and increased activity of intracellular proteolytic enzymes that degrade the muscle cell. Intracellular constituents are then 


\section{CLINICAL PRACTICE}

extruded into the extracellular fluid and plasma. ${ }^{10}$ Excess myoglobin is nephrotoxic.

In this patient, rhabdomyolysis is evidenced by the increased plasma myoglobin level as well as the appearance of cola-colored urine which is characteristic of myoglobinuria. In addition, the patient tested positive for urine hemoglobin in the absence of red blood cells. The immediate consequence of rhabdomyolysis is hyperkalemia, resulting from the release of intracellular potassium, which can contribute to cardiac arrhythmia, and hypocalcemia due to calcium binding by damaged muscle proteins. ${ }^{10}$ In this patient, hyperkalemia was not evident although it may have been offset by the hypokalemia induced by hyperglycemia. Hypocalcemia persisted for 72 hours.

Acute renal failure develops in $30-40 \%$ of patients with rhabdomyolysis. It is the most serious complication of rhabdomyolysis and results from heme protein nephrotoxicity, myoglobin cast formation within the renal tubules and renal vasoconstriction. ${ }^{10}$ In this patient, indications of acute renal failure were evident in the steadily rising BUN and creatinine levels and declining GFR.

Vascular occlusions, such as myocardial infarcts, are another important complication of HHS, which occur due to the altering effect that hyperosmolality and hypernatremia have on factor VIII and the hypercoagulable state already produced by increased viscosity. ${ }^{2}$ In this patient, total serum $\mathrm{CK}$ as well as the CK-MB fraction were elevated. Although CK-MB is relatively cardiac-specific, $\mathrm{CK}-\mathrm{MB}$ is expressed in skeletal muscle and thus, CK-MB values in the context of rhabdomyolysis are confounded. CK-MB levels can be indexed to total $\mathrm{CK}$ to create a relative index. Relative index $=$ (CK-MB mass/ total CK activity) $\mathrm{x} 100$. In this patient the CK-MB index remained within the reference interval despite the elevation of total CK. However, it is important to note that when there is concomitant skeletal muscle injury, as in this patient, the sensitivity for CK-MB to detect cardiac injury is lost. ${ }^{11}$ Thus, the elevated total CK due mainly, but not entirely to the CK-MM isoform originating from skeletal muscle, can mask the diagnostic utility of CK-MB in detecting cardiac events. TnI, a more sensitive and specific cardiac marker, was initially within reference limits but became elevated on day 2 . This result was investigated and an acute non-ST elevation myocardial infarction was confirmed with ECG and echocardiogram. The patient was placed on aspirin and heparin and scheduled for a stress test following discharge.

\section{TREATMENT}

The American Diabetes Association protocol for treatment of patients with HHS begins with vigorous IV rehydration followed by electrolyte replacement, insulin administration and treatment of coexisting conditions. Electrolyte replacement is necessary prior to insulin treatment since insulin promotes influx of sodium and potassium as well as glucose, into cells, further exacerbating hyponatremia and hypokalemia. ${ }^{1}$ Immediate intravascular volume resuscitation is recommended to prevent rhabdomyolysis-induced renal injury. Volume expansion is performed in an effort to increase GFR as well as dilute myoglobin and other nephrotoxins released in rhabdomyolysis. Increased renal flow also improves oxygen delivery to ischemic renal tissue. Care must be taken to avoid cerebral edema and congestive heart failure due to overhydration, particularly in patients with renal impairment.

Administration of IV sodium bicarbonate is also recommended to alkalinize the urine, thereby increasing the solubility of myoglobin and decrease precipitation within the renal tubules.' Unfortunately, neither treatment was able to prevent significant renal damage in this patient. As can be seen in Table 1, the patient's renal function continued to decline although electrolytes, $\mathrm{pH}$ and glucose were normalized.

The patient was discharged after a three week hospital stay with insulin, aspirin, metoprolol, gabapentin, and pantoprazole. Ongoing dialysis treatment was initiated. His pancreatitis persisted after antibiotic treatment and will be managed with diet and evaluated at a later date. The patient is ambulatory with assistance and attends physical therapy.

\section{REFERENCES}

1. Stoner GD. Hyperosmolar hyperglycemic state. Am Fam Physician. 2005;71(9):1723-30. 


\section{CLINICAL PRACTICE}

2. Delaney MF, Zisman A, Kettyle WM. Diabetic ketoacidosis and hyperglycemic hyperosmolar nonketotic syndrome. Endocrinol Metab Clin North Am. 2000;29(4):683-705.

3. Chu CH, Lee JK, Lam HC, Lu CC. Prognostic factors of hyperglycemic hyperosmolar nonketotic state. Chang Gung Med J. 2001 24(6):345-51.

4. English P, Williams G. Hyperglycaemic crises and lactic acidosis in diabetes mellitus. Postgrad Med J. 2004;80(943):253-61.

5. Lawence RD. Renal threshold for glucose: normal and in diabetics. Br Med J, 1940,1;766-8.

6. Matz R. Management of the hyperosmolar hyperglycemic syndrome. Am Fam Phy. 1999; 60:1468-76.

7. Bayer HealthCare. Multistix 10 SG reagent strips package insert. 2005.

8. Taboulet R, Deconinck N, Thurel A, Haas L, Manamani J, Porcher R, et al. Correlation between urine ketones (aceto- acetate) and capillary blood ketones (3-beta-hydroxybutyrate) in hyperlycaemic patients. Diab and Metab. 2007;33(2):135-9.

9. Fernandez WG, Hung O, Bruno GR, Galea S, Chiang WK. Factors predictive of acute renal failure and need for hemodialysis among ED patients with rhabdomyolysis. Am J Emerg Med 2005;23(1):1-7.

10. Walter LA, C.M., Rhabdomyolysis. Hosp Phy. 2008; 44(1):25-31.

11. el Allaf M, Chapelle JP , el Allaf D, Adam A, Faymonville ME, Laurent $\mathrm{P}$, et al. Differentiating muscle damage from myocardial injury by means of the serum creatine kinase $(\mathrm{CK})$ isoenzyme $\mathrm{MB}$ mass measurement/total CK activity ratio. Clin Chem. 1986;32(2):291-5.

\section{Helping families to be better patients.}

For ten years, Lab Tests Online has been helping families to better understand their laboratory tests so that they can speak with their doctors more effectively about the care they are receiving.

We want to thank our Sponsors and Partners from the

lab community for their support in making

Lab Tests Online available to over
24 million visitors in 2010.

Contact 2labtestsonline@aacc.org

to become a sponsor and join our

10th-year celebration at AACC in Atlanta.

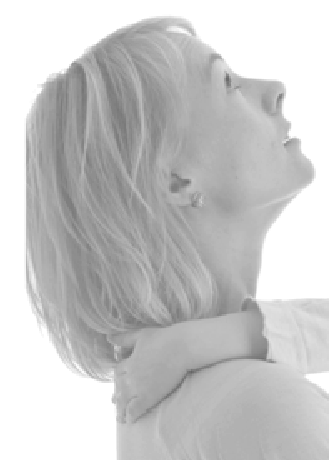

www.labtestsonline.org
Sponsors

Beckman Coulter

Roche Diagnostics

Siemens Healthcare Diagnostics

Abbott Diągnoștics

Spectra Laboratories

Phadia

Fujirebio Diagnoștics

Hycor Biomedical

ITC

PAML

Randox

Sebia Electrophoresis

Sysmex

Professional Co-op

DRG International, Inc.

$\begin{array}{ll}\text { Partners } & \text { CSMLS } \\ \text { AACC } & \text { CSCC } \\ \text { ASCLS } & \text { CLSI } \\ \text { ASM } & \text { NACB } \\ \text { CLMA } & \text { Joint Commission } \\ \text { ASH } & \text { APHL } \\ \text { AMP } & \text { AABB } \\ \text { ASCP } & \text { AAB } \\ \text { CAP } & \text { AAFP-PT }\end{array}$

